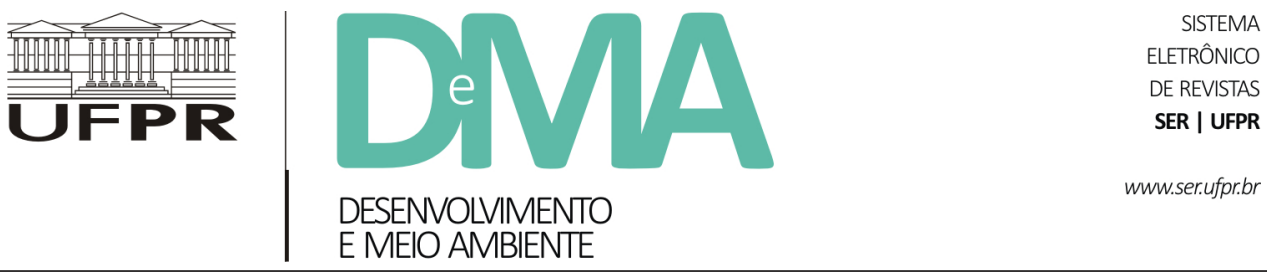

\title{
O erro histórico da ciência econômica: um resgate da obra de Georgescu-Roegen
}

\section{The historical error of economic science: a rescue of Georgescu- Roegen's work}

\author{
Jefferson Marçal da ROCHA ${ }^{1 *}$, Silvio Cezar AREND² \\ ${ }^{1}$ Universidade Federal do Pampa (UNIPAMPA), São Gabriel, RS, Brasil. \\ ${ }^{2}$ Universidade de Santa Cruz do Sul (UNISC), Santa Cruz do Sul, RS, Brasil. \\ *E-mail de contato: jeffersonmrocha@gmail.com
}

Ensaio recebido em 8 de abril de 2019, versão final aceita em 24 de setembro de 2019.

RESUMO: Este ensaio faz uma retomada histórica da obra do economista romeno Nicholas Georgescu-Roegen, considerado um dos mentores da Economia Ecológica e esquecido no seu tempo. Utilizando-se de referencial bibliográfico e partindo de uma análise crítica da concepção da Economia Neoclássica, sustenta-se que os erros do mainstream econômico se devem a uma visão míope sobre a utilização dos recursos naturais, um erro na abordagem da utilização do fator de produção natureza $(\mathrm{N})$, percebido por Roegen na década de 1960 e jamais levado em conta pelos economistas ortodoxos. Assim este erro fundamentou toda uma escola científica, originando uma "miopia" analítica coletiva de seus seguidores. Trata-se de uma análise parcial da obra do "professor dos professores", como foi chamado Georgescu, e um desafio provocativo a outros pesquisadores que porventura tenham outra visão à perspectiva defendida aqui.

Palavras-chave: economia ecológica; recursos naturais; energia; economia neoclássica.

ABSTRACT: This essay makes a historical resumption of the work of the Romanian economist Nicholas GeorgescuRoegen, considered one of the mentors of the Ecological Economics but forgotten in his time. By using a bibliographical reference and starting from a critical analysis of the Neoclassical Economics conception, it is maintained that the errors of the economic mainstream are due to a myopic view on the use of the natural resources, an error in the approach of the use of the production factor nature $(\mathrm{N})$. Roegen noticed this in the 1960s, but orthodox economists never took into account. Thus this error grounded a whole scientific school, originating a collective analytic "myopia" of its followers. This is a partial analysis of Georgescu-Roegen's 
works, the "teacher of teachers", and a provocative challenge to other researchers who may want to oppose the perspective defended here.

Keywords: ecological economics; natural resources; energy; neoclassical economics.

A economia neoclássica analisava o crescimento econômico em capital, mão de obra e progresso técnico. Mas hoje creio que seria mais esclarecedor conceber os principais propulsores da economia como energia e ideias (Martin Wolf).

\section{Introdução}

Intencionalmente a epígrafe desde texto traz a citação de um jornalista econômico ortodoxo, editor da Financial Times, que não é um dos teóricos utilizados aqui, mas a colocamos como uma primeira reflexão para instigar a percepção de que a problemática ambiental passou nas últimas décadas a ser um tema que, mesmo nas diferenças ideológicas e/ ou teóricas, perpassa todos os intelectuais sérios, mesmo que as enormes divergências conceituais os levem às mais variadas soluções.

Feita esta ressalva, este texto traz uma síntese do pensamento do matemático e economista romeno Nicholas Georgescu-Roegen, que viveu entre 1906 e 1994, portanto um intelectual do século XX e que talvez tenha sido o pensador das ciências sociais mais injustiçado de todos os tempos. Quando salientamos a injustiça, referimo-nos à científica, em especial a da ciência econômica, pois se considera que, se a perspectiva teórica de Georgescu-Roegen, no que se refere ao tratamento dos recursos naturais $(\mathrm{RN})$, tivesse sido levada em conta quando ele salientou em meados da década de 1960 sobre os limites das análises econômicas convencionais para este tema, possivelmente teríamos uma trajetória de desenvolvimento diferente da que tivemos na segunda metade do século XX, ou, de outra forma, talvez já estivéssemos vivendo com outros padrões de consumo, com outras possibilidades: menos materialistas, menos poluidoras, mais sustentáveis? Mais felizes? Quem sabe? Mas, certamente, já teríamos respostas mais efetivas, especialmente da ciência econômica, para os graves problemas ambientais que temos no século XXI e com ainda poucas perspectivas de solução.

Nesta introdução começamos fazendo uma breve síntese da sua trajetória de vida, porque se acredita que toda obra intelectual sempre é reflexo de uma conduta ideológica e política.

Georgescu foi um prodígio e, como todos os europeus do seu tempo, influenciado pelas duas grandes guerras mundiais. $\mathrm{O}$ primeiro fato que $\mathrm{o}$ marcou foi quando tinha 10 anos de idade, a transferência do começo de seus estudos preparatórios, do ano de 1916, após conseguir uma bolsa de estudo, para o ano de 1918, após o final da Primeira Grande Guerra Mundial. Entre 1918 e 1926 estudou na capital romena, formando-se em Matemática na Universidade de Bucareste e, com apenas 20 anos, foi estudar, também com bolsa de estudo, na Universidade Sorbonne em Paris. Lá passou da matemática para estatística, onde desenvolveu a tese de doutoramento com o tema: "os componentes cíclicos de um fenômeno", que foi publicada na íntegra no jornal da Sociedade de Estatística de Paris. Após este 
trabalho, que teve relativa repercussão, foi estudar dois anos em Londres com o renomado estatístico Karl Pearson. Desta convivência concluiu que todo o pesquisador deve, antes de tudo, compreender filosofia, pois a representação "do mundo real é a questão primária de qualquer esforço científico" (Cechin, 2010, p. 46).

A repercussão de sua tese sobre fenômenos cíclicos lhe rendeu um convite para estudar em Harvard, em conjunto com um grupo de economistas que se empenhavam na época em pesquisas sobre Barômetro Econômico. Porém, logo que chegou, descobriu que o projeto não mais existia. Antes de retornar à Romênia após esta decepção, pediu uma audiência com o já na época conhecido economista austríaco Joseph Schumpeter e esta foi uma conversa crucial na carreira de Georgescu, pois Schumpeter o aceitou como aluno, mesmo que suas pesquisas não fossem de uma mesma área de conhecimento.

A convivência com Schumpeter o transformou em um economista. Os dois anos que conviveu intelectualmente (1934-1936) com o mestre serviram para reforçar sua convicção de que os processos econômicos são parte de uma trajetória histórica e, portanto, impossíveis de serem descritos, fidedignamente, apenas pela matemática, o que parece, já na época, que os economistas haviam esquecido.

Nos dois anos em Harvard, Georgescu escreveu quatro importantes artigos sobre a teoria do consumidor e da produção e, apesar de receber convite para permanecer nesta universidade como docente, voltou para a Romênia em 1937, onde ocupou vários cargos no governo. Só deixou seu país quando em 1948 o Partido Comunista assumiu o governo romeno. Neste ano voltou para os Estados Unidos como professor convidado da Universidade de Vanderbilt, na cidade de Nashville, no Tennesse, onde viveu todo o resto de sua vida, até 1994.

Georgescu não criou nenhuma escola do pensamento econômico. Alguns alegam que isto se deve a, no mínimo, dois fatores: um pela sua personalidade irascível e sua falta de habilidade política na academia, o que fez com que poucos conseguissem convívio mais próximo com ele (apenas um aluno defendeu tese de doutorado com Georgescu, o brasileiro Ibrahim Eris); outro fator, mais simbólico, foi o comentário do já consagrado economista na época Paul Samuelson, segundo ganhador do Prêmio Nobel de Economia em 1970, na décima edição do livro Economics em 1976, em que alertava os estudantes de economia de que os trabalhos de Georgescu, antes considerados seminais pelo próprio Samuelson, não tinham mais valor, pois o "professor dos professores"1 estava iludindo-se em buscar explicações econômicas na, considerada por ele, 'obscura' ecologia.

Espera-se, condensando de forma muito breve uma teoria que deveria estar nas primeiras aulas do curso de economia, mas que pelos descaminhos do destino acabaram deixando-a por mais de quatro décadas no ostracismo, contribuir no resgate da obra de um dos intelectuais mais perspicazes no que se refere à compreensão do uso dos recursos naturais. Mas talvez tarefa mais importante aqui seja instigar outros estudiosos do tema a também se aventurarem a estudar e discutir a obra de um dos economistas mais importantes do século XX.

\footnotetext{
${ }^{1}$ Professor dos professores foi o adjetivo que o próprio Paul Samuelson deu a Georgescu-Roegen no prefácio da obra deste último Analytical Economics, em 1966.
} 
Além desta introdução, este ensaio está composto de mais três tópicos: no próximo se faz uma análise dos argumentos da teoria econômica clássica encontrada nos manuais desta ciência, argumentos que explicam os motivos da inexistência de uma escola "georgescuniana"; no seguinte se estabelece uma relação entre a energia, fenômeno fundamental na obra de Nicholas Georgescu-Roegen, e a economia, abordando os princípios da denominada Economia Ecológica, que o tem como um dos seus precursores, apesar dele não ter nunca utilizado esta expressão. E por fim, nas considerações finais, faz-se um resgate analítico do tema do ensaio, à luz do referencial utilizado nos tópicos anteriores, bem como se apontam os limites desta investigação, direcionando o leitor para os possíveis temas de pesquisa que poderão ser motivados pela leitura deste trabalho.

\section{Por que os manuais de economia esqueceram Georgescu?}

Os manuais geralmente procuram ilustrar para o iniciante na matéria um modelo. Na medicina, por exemplo, isto é mais explícito, quando os professores usam réplicas de plástico (ou outro material semelhante) para representar a realidade de órgãos humanos. Já na economia a representação é pura abstração, onde diagramas, gráficos e equações materializam imagens ilustradas da vida em sociedade e, aparentemente, permitem uma visão do que é considerado realmente importante para os iniciantes na ciência econômica.

Para Mankiw, autor do manual de economia mais usado nas escolas de economia brasileiras atualmente (entre as décadas de 1980-2010), o ob- jetivo de seu livro é " $[\ldots]$ transmitir esta forma de pensar ao público mais amplo possível e convencer os leitores de que ela ilumina parte do que está a nossa volta" (Cechin, 2010, p. 11). Nesta pequena passagem do manual de Mankiw, já temos dois indicativos do porquê do esquecimento do nosso autor (Georgescu): primeiro, a escolha do que é importante convencer os leitores do que se deve estudar; segundo, os manuais são omissos em relação a temas da fronteira do conhecimento, não há a intenção de se avançar nas teorias da disciplina, pois, como salienta Cechin (2010, p. 20), "Como poderiam (os professores) transmitir o núcleo básico de ideias se todas as dúvidas surgidas com o avanço da ciência estivessem presentes?" (acréscimos nossos).

Vamos ser mais explícitos em relação aos indicativos acima. Os manuais de economia então trazem escolhas ideológicas do que os futuros economistas devem aprender, ou seja, no caso da economia neoclássica, manter a lógica da economia capitalista! No outro indicativo, os economistas não querem ensinar nada de novo, pois, ou não sabem, ou há um receio de se descobrir que o fundamento que formou a sua ciência está errado!

Vamos então para os fundamentos da economia. O principal deles e que possivelmente esteja no programa do primeiro dia de aula dos cursos das ciências sociais aplicadas já há mais de um século, é o diagrama do fluxo circular, que ilustra, metaforicamente, a relação entre o mercado de bens e o mercado dos fatores de produção (Figura 1). Neste diagrama (ilustrado abaixo), aparecem dois fluxos, um dos fatores de produção e de bens e serviços e outro dos rendimentos (monetário). Os donos dos fatores de produção são as famílias, que os emprestam/cedem e recebem para isto salários, arrendamentos e lucros das empresas para que estas 
produzam os bens e serviços que são ofertados em um mercado de bens e serviços (Mankiw, 1999).

Esta visão é um modelo de relações de troca em um sistema fechado e isto será importante na teoria de Georgescu. Não há outras entradas a não ser a dos fatores de produção e não tem outras saídas a não ser a de bens e serviços gerados por aqueles. $\mathrm{O}$ mundo parece perfeito assim. Mas esta representação não é a verdadeira. Sua base conceitual é falsa. Existem outras entradas, outras saídas, outro fluxo, que os economistas nunca enxergaram/ão: a energia (Georgescu-Roegen, 2012). Voltaremos a ela mais tarde no tópico seguinte.

Na primeira obra relevante do filósofo, depois considerado o pai da economia moderna, Adam Smith, A teoria dos sentimentos morais, ele parte do pressuposto que a educação poderia tornar a todos, inclusive os trabalhadores livres, em filósofos. Ou seja, seres capazes de refletirem sobre sua própria práxis. Karl Marx, quase um século depois, apesar da notória discordância com a teoria smithiniana, levou esta perspectiva mais adiante, condenando que o afastamento da consciência da práxis levava o ser humano, o trabalhador no sistema de produção capitalista, a se transformar em um mero apêndice da máquina. Para Marx, conscientizar-se disto era o único caminho para a "des-alienação" do trabalhador. E esta consciência da exploração que o trabalhador sofre com a lógica capitalista de produção de bens econômicos, era a transformação social dialética do capitalismo $\rightarrow$ socialismo $\rightarrow$ comunismo, prevista por Marx.

$\mathrm{Na}$ teoria destes dois economistas clássi$\cos ^{2}$, mesmo com notória diferença de concepção

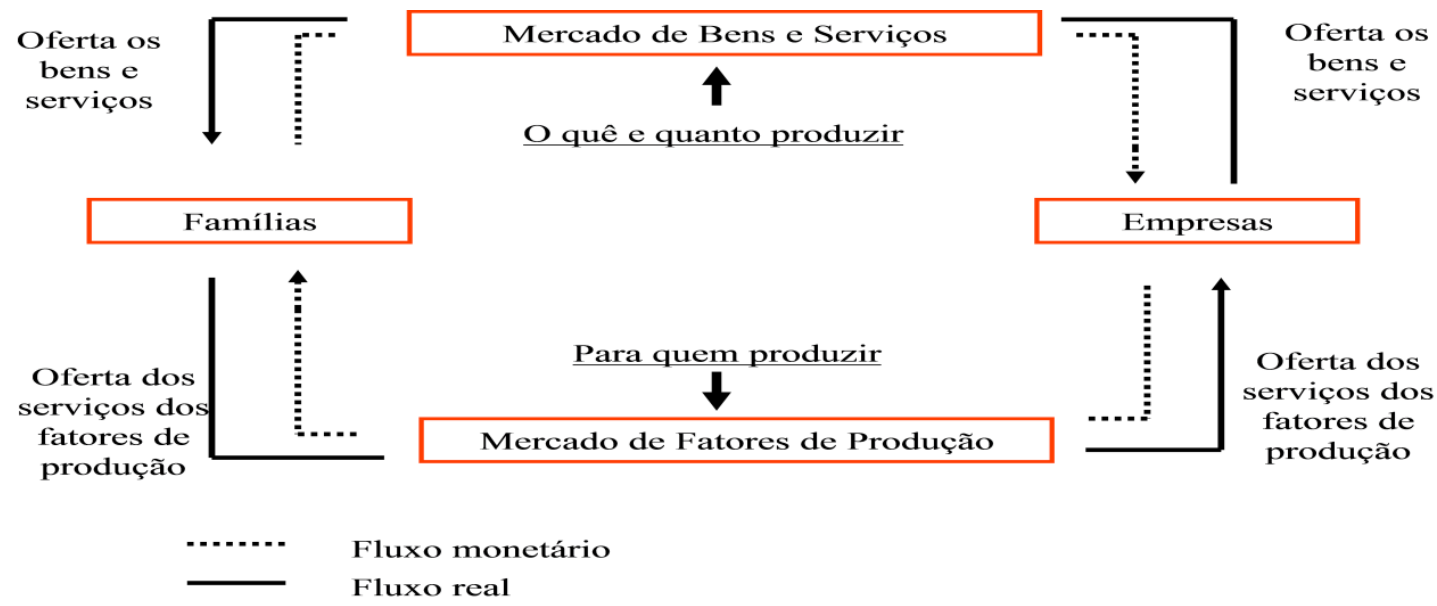

FIGURA 1 - Fluxo circular de bens e recursos econômicos em uma economia de mercado liberal.

FONTE: Mankiw (1999).

\footnotetext{
${ }^{2}$ Usa-se esta expressão apesar de considerar que Marx jamais se intitulou economista e, talvez, abominasse ser considerado um clássico da economia como Smith, contudo muitos livros didáticos de sociologia, filosofia e economia os colocam lado a lado no que se refere à referência de economistas clássicos.
} 
política e ideológica entre eles, está explicita a configuração da economia como filosofia. E por que esta percepção foi abandonada? Fazendo dos economistas meros "cientistas/técnicos" de interpretação da economia capitalista? Esta era uma das inquietações de Nicholas Georgescu-Roegen, pois, para ele, enquanto na física, a mais racional de todas as ciências, os seus estudiosos passaram, já no princípio do século XX, a filosofar sobre sua própria epistemologia, na ciência econômica havia uma enorme resistência em confrontar as bases da própria Episteme.

A epistemologia mecanicista foi a maior inspiração dos economistas neoclássicos (Georgescu-Roegen, 2012, p. 73-75). Foram poucos os economistas do século XX que se atreveram a ir contra este consenso.

Para Georgescu muitas questões supostamente vistas como exclusivas dos estudos dos economistas não mais poderiam ser interpretadas apenas com as bases nesta ciência, especialmente em relação ao uso dos recursos naturais. De todas as outras áreas do conhecimento é à Física que se deveria dar especial atenção, pois são questões que dizem respeito às mudanças qualitativas que são estruturais, contraponto às mudanças que envolvem apenas variações de quantidade, tão comum nas análises econômicas clássicas (Georgescu-Roegen, 2012).

Seguindo os preceitos do seu tutor na economia, Joseph Schumpeter, Georgescu sugere que o mais importante para as mudanças estruturais são as inovações e estas para um sistema econômico são muito mais de ordem qualitativa do que quantitativa. Schumpeter foi um dos primeiros economistas a denunciar a ineficiência das bases tecnológicas do sistema de produção de riquezas no capitalismo, daí seu pessimismo quanto ao futuro deste, pois métodos ineficientes podem manter-se por longos períodos, desde que o mercado absorva estas ineficiências. Vale uma passagem magistral da sua principal obra, sobre este tema:

Os "coeficientes de produção" representam a relação quantitativa dos bens de produção numa unidade de produto, e, portanto, são uma característica essencial da combinação. Nesse ponto o elemento econômico contrasta agudamente com o tecnológico (Schumpeter, 1997, p. 33).

Georgescu condenou o excessivo formalismo matemático da economia. Mesmo sendo matemático de formação, considerava que esta característica, comum entre os economistas da sua época, deixava os aspectos verdadeiramente interessantes fora das análises. Em relação à importância da perspectiva histórica, sentenciou:

Eu estaria entre os últimos servos da ciência a negar o papel indispensável da teoria, que deve necessariamente aspirar a ser quantitativa e, portanto, matemática, uma vez que a teoria não está separada da realidade. Todavia, como meu mestre Joseph Schumpeter fez com tanta sagacidade, eu estaria entre os primeiros a defender a necessidade absoluta de estudos históricos e institucionais na ciência social, portanto, na economia. (Georgescu-Roegen, Energy and Economic Myths, In: Cechin, 2010, p. 58-59).

Talvez o marco da transformação efetiva da economia como filosofia para o caráter mecânico do tratamento das questões sociais, foi a chamada Revolução Marginalista ocorrida entre o final do século XIX e início do século XX, que definitivamente consolidou o entendimento mecânico dos fenômenos econômicos. A premissa era que as trocas entre indivíduos que buscavam maximizar seus interes- 
ses levariam naturalmente a um equilíbrio social ou, de outra forma, a maximização dos interesses individuais levaria a um benefício social geral. A concepção desta teoria era que existe no sistema social um ponto de equilíbrio em que as forças que agem sobre o sistema se cancelam com a força de cada agente individual. Um mundo perfeito!

Todas as versões da teoria neoclássica (escolas francesas, austríacas, inglesa) partem de uma mesma suposição, a economia é formada por uma gama de agentes econômicos que se constituem em consumidores e produtores racionais possuidores de preferências de "escala de utilidade". A tarefa foi então comprovar que o mecanismo de mercado capitalista faz um casamento perfeito entre o emprego dos fatores de produção e a satisfação dos consumidores, que para estes são a própria sociedade (Prado, 2001).

Outra percepção mecânica/matemática da economia é a também clássica fórmula da função da produção, para a qual vale a pena aqui remetermos a uma passagem do já citado manual de Mankiw (1999, p. 538):

Suponha que Y denote a quantidade de produtos, L, a quantidade de trabalho, $\mathrm{K}$, a quantidade de capital humano, e N, a quantidade de recursos naturais. Então podemos escrever $\mathrm{Y}=\mathrm{A} . \mathrm{F}(\mathrm{L}, \mathrm{K}, \mathrm{H}, \mathrm{N}), \quad$ onde F ( ) é uma função que mostra como os insumos são combinados para gerar o produto. "A" aumenta, de modo que a economia produz mais a partir de qualquer combinação dada de insumos.

Nos anos de 1960, meio século antes desta citação, Georgescu já lamentava que a formulação matemática da produção tivesse chegado a ponto de desrespeitar um pré-requisito da ciência: ter uma ideia clara sobre a correspondência dos símbolos na realidade. E este é o principal problema da função da produção, pois nela não constam as transformações qualitativas, que naturalmente ocorrem como consequência das mudanças quantitativas nos insumos e produtos.

A função de produção trata o K, por exemplo, como uma medida em capital homogêneo, não leva em conta que em um processo mais intensivo em capital haverá sempre uma mudança na qualidade. Não faz sentido, por exemplo, supor que uma operação de escavação mais intensiva em capital signifique multiplicar o número de pás diminuindo a participação de trabalhadores. Então a chamada elasticidade-substituição fica sem sentido na relação entre capital e trabalho e, menos ainda, a relação de qualquer fator com $\mathrm{N}$ (recursos naturais). Neste último, o erro ainda é maior, pois pode se supor que haveria condições de produzir bens sem o uso de recursos naturais $(\mathrm{N})$, desde que se aumentasse o uso dos demais fatores de produção. Um erro matemático sem justificativa racional.

Até o último quarto do século XX, o mainstream neoclássico não considerava os recursos naturais nem como fonte de insumos, nem como suporte de assimilação de impactos (fossa de resíduos). Por isso, em longo prazo, não representavam limites absolutos à expansão da economia. Inicialmente, esses recursos sequer apareciam em suas representações analíticas da realidade econômica, como, por exemplo, na especificação de função de produção onde entravam apenas o capital e o trabalho. "A economia funcionava sem os recursos naturais" (Romeiro, 2003, p. 7). Para Romeiro (2003, p. 7):

Com o tempo, os recursos naturais passaram a ser incluídos nas representações de função de produção, mas mantendo a sua forma multiplicativa, o que 
significava a substitutibilidade perfeita entre capital, trabalho e recursos naturais, e, portanto, a suposição de que os limites impostos pela disponibilidade de recursos naturais podem ser indefinidamente superados pelo progresso técnico que os substitui por capital (ou trabalho). Em outras palavras, o sistema econômico é visto como suficientemente grande para que a disponibilidade de recursos naturais $(\mathrm{RN})$ se torne uma restrição à sua expansão, [....].

Tal suposição foi incorporada à função de produção, a qual é representada matematicamente por: $\mathrm{Y}=\mathrm{f}(\mathrm{K}, \mathrm{L}, \mathrm{R})$, em que a quantidade de recursos naturais $(\mathrm{R})$ requerida pode ser tão pequena quanto se deseja desde que a quantidade de capital $(\mathrm{K})$ seja suficientemente grande. Nesse caso, a perpetuação da expansão econômica seria viável em qualquer prazo.

O progresso científico é capaz de se mover, sem traumas significativos, de uma base de recursos para outra ininterruptamente, à medida que fossem os recursos se esgotando. A forma produtiva até então utilizada iria permitir que surgissem novos mecanismos, mais aptos a maximizarem a utilização dos recursos naturais. Sendo assim, o progresso científico e tecnológico é a variável principal para se garantir um processo de substituição ilimitada e o crescimento econômico em longo prazo.

Para Georgescu, a denominada produção deveria ser chamada de transformação, pois é isto que acontece com os elementos da natureza no processo econômico, seria preciso discernir o que entra e sai relativamente inalterado do processo produtivo, daquilo que se transforma brutalmente dentro dele.

Com os economistas neoclássicos, a partir do final do século XIX, a produção passou a ser vista como uma escolha ótima de alocação de fatores de produção; assim, o escopo da economia, como prática científica, passou a ser apenas a alocação de meios escassos entre fins alternativos e isto os deixou com uma fenda (ou seria uma miopia?) nos seus paradigmas científicos. Nesta abordagem os fatores que servem à produção/transformação passaram a ser vistos com a mesma natureza e a substituição entre eles não teria limites, e com isto o fluxo de recursos naturais poderia ser indefinidamente substituído por capital.

É difícil acreditar que todos os economistas formados a partir da metade do século XX acreditaram que o potencial do fator capital de sustentar uma utilização menor de recursos naturais era um exemplo coerente de substituição. Uma máquina mais eficiente na transformação de recursos naturais em bens e serviços está de fato diminuindo o desperdício, mas nada garante a redução de resíduos, além disto, deve-se considerar que uma máquina mais eficiente sendo adicional exigiu a utilização de recursos materiais e energéticos em sua produção.

O economista britânico W. S. Jevons já havia salientado no final do século XIX (1865), na sua obra sobre o Problema do Carvão, que a melhoria tecnológica levaria quase que inevitavelmente a um "efeito bumerangue", como também ficou conhecido o paradoxo de Jevons, pois a constatação de maior eficiência produtiva com o uso de melhores tecnologias levaria, pela lógica maximizadora de lucro do capitalismo, a um aumento de consumo e, como consequência direta, maior expansão no uso de recursos naturais e aumento dos resíduos (poluição) (Jevons, 1965).

Vale salientar que o século XX consolidou o método fordista de produção de bens e este parte basicamente de dois pressupostos interligados: os constantes aumentos de produtividade advindos dos ganhos da produção em série e a incorporação de 
uma classe trabalhadora ao mercado consumidor para dar vazão a esses ganhos. Esta perspectiva produtiva prevaleceu até as últimas décadas do século XX sem contestação, pouco se avançou sobre as relações entre crescimento econômico e degradação dos recursos naturais. Também não houve preocupações muito significativas sobre os problemas gerados pelo processo produtivo em temas como superprodução, massificação do trabalho, descartes, etc., temas que ficam obscuros nas análises ortodoxas dos economistas do século XX. Diante do sucesso do método Ford ${ }^{3}$, poucos cientistas consideravam os problemas com os desgastes dos recursos naturais como sendo objeto importante de estudos e, muito menos ainda, os cientistas econômicos (Rocha, 2011; Souza, 2000).

Uma das maiores distorções da abordagem neoclássica da economia é ignorar o fluxo inevitável de resíduos e apostar na substituição sem limites dos fatores de produção. Esta abordagem, definitivamente, transformou a economia de uma perspectiva filosófica para uma técnica mecanicista na busca de maior eficiência. E esta ainda com uma duvidosa coerência racional.

\section{A energia, a economia e a sustentabilidade}

Como prometemos no tópico dois, voltamos aqui ao tema Energia, pauta crucial para a compreensão da obra de Georgescu-Roegen e quase que desconsiderado por completo nas análises dos economistas do mainstream.
No início da década de 1970 nosso autor destacava que a primeira lei da termodinâmica diz que não se pode criar nem destruir matéria ou energia. Assim ele indagou: como é então o processo econômico de produção de riquezas deste sistema? A resposta óbvia é: absorve, transforma qualitativamente a energia de baixa entropia e lança-a para fora do sistema na forma de alta entropia. A conclusão a que chegou foi que o sistema econômico é um subsistema do ecossistema global finito, dependendo dele para extrair energia (baixa entropia) e usá-la devolvendo-a em forma de outra forma de energia (alta entropia).

\begin{abstract}
Ao contrário da visão newtoniana, em que um sistema apresenta reversibilidade temporal, permanecendo idêntico; a segunda lei da entropia indica uma mudança qualitativa unidirecional e irrevogável: a magnitude de energia não disponível de um sistema fechado aumenta continuamente. Para diminuirmos a entropia de um sistema, necessitamos obter energia do exterior, o que implica aumentar o déficit entrópico global (Fuks, 2012).
\end{abstract}

No contexto político internacional, nos primeiros anos da década de 1970 a questão energética assumiu uma das pautas mais importantes no que se refere aos problemas econômicos internacionais. A crise do petróleo, o relatório Limites do Crescimento e o movimento ambientalista global internacionalizaram a problemática socioambiental. Uma nova pauta estava colocada, agora ligando contextos sociais, econômicos e ambientais.

Nicholas Georgescu-Roegen participou ativamente deste debate. Seus artigos passaram a se popularizar em áreas como ecologia, ciências

${ }^{3}$ Consideramos que os métodos produtivos incorporados às organizações durante o século XX são variáveis do fordismo, mesmo os “japoneses” toyotismo, just-intime, etc. Não cabe aqui argumentos mais profundos neste tópico, que ficará para outras investigações. 
ambientais, física, etc., exceto na economia, talvez porque o problema da manutenção econômica do sistema vigente justamente era a adequação da oferta de recursos naturais para sustentar os padrões de consumo ocidental. Os economistas do mainstream, que dominavam os organismos de desenvolvimento nacionais e internacionais, sem praticamente nenhuma contestação, continuavam otimistas, pois se recusavam a admitir que houvesse relação entre escassez de recursos e o processo produtivo do capitalismo.

Georgescu-Roegen havia salientado na década anterior que os recursos naturais são na verdade matéria e energia com uma determinada qualidade que entram no processo econômico e transformam-se. Poluição, calor e matéria dissipados saem deste processo econômico sem praticamente nenhuma outra utilidade. Entender esta transformação é compreender os princípios da segunda lei da termodinâmica, tema pouco comum entre cientistas sociais. Sem nos alongarmos nesta temática aqui e focando-nos no que nos interessa por ora; como síntese pode-se afirmar que o princípio da termodinâmica é considerar que a energia usada hoje, que serve a uma elite econômica (como a dos combustíveis fósseis, em um exemplo óbvio) não estará mais disponível no futuro; de outra forma, bem mais provocativa, pode-se afirmar que a gasolina dissipada para mover os automóveis da classe média e os jatos particulares da rica não poderá ser usada para cozinhar os alimentos dos pobres do continente africano ou da América do Sul ou de qualquer outro lugar, nem hoje nem no futuro.

Este princípio coloca por terra a base do conceito mercadológico, vendido pelos organismos internacionais como viável, o chamado desenvolvimento sustentável, que não coloca em xeque os atuais padrões de crescimento econômico e, por consequência, de uso e consumo energético. Não se pode negar que desenvolvimento requer energia. Pelo menos nos moldes que se configurou este tema no século XX. E é ela que conecta os desafios da sustentabilidade ambiental com as dimensões social e econômica.

$\mathrm{Na}$ chamada visão otimista, mas sóbria, de autores como George Monbiot (2004) e Lester Brown (1983), há o reconhecimento de que é urgente a necessidade de mudanças de infraestrutura socioeconômica na produção e consumo capitalista para que a demanda de energia seja diminuída. $\mathrm{O}$ adjetivo sóbrio dos autores supracitados, nesta perspectiva, se junta ao realismo sombrio nosso, de que não haverá mudanças significativas para fontes renováveis que sejam capazes de manter os atuais níveis de consumo em um prazo curto/médio. Em alguns casos, como no Reino Unido, por exemplo, estudado por Monbiot (2004), seriam necessários cortes de até $90 \%$ da emissão de gases que causam o efeito estufa até o ano de 2030. Quadro pouco provável até esta data, mesmo considerando os avanços tecnológicos do presente. Assim,

\begin{abstract}
A busca de um perfil energético mais sóbrio depende, entre outras coisas, de mudanças de estilo de vida, nos padrões de consumo e na organização do espaço e do aparelho produtivo, da reestruturação dos espaços urbanos, da durabilidade dos produtos e da melhor manutenção das infraestruturas. Assim, o otimismo não é tanto em relação à viabilidade das tecnologias de energia alternativas, mas principalmente em relação à possibilidade de reestruturar os modos de vida das nações industriais avançadas (Cechin, 2010, p. 189).
\end{abstract}

Há uma outra questão importante além da perspectiva energética: a depleção dos depósitos 
terrestres de materiais, causada por todos os processos produtivos. Em um planeta fechado, como a Terra, é inevitável que a matéria residual, gerada nas sobras da produção, é um problema talvez maior que a energia dissipada, um passivo que as gerações futuras receberão.

A otimista possibilidade proposta por Boulding de economia astronauta (reciclagem total de resíduos), que contrapõe à economia cowboy (expansão infinita das fronteiras), mesmo válida, por denunciar que a felicidade humana não pode estar atrelada ao consumo infinito de materiais, a ideia de uma economia cíclica de autorreprodução, viabilizada apenas pela entrada líquida de energia solar capaz de reciclar todos os materiais é também contestada por Georgescu. Para ele, uma economia circular só seria possível sem a entrada de novos materiais, pois a matéria prima utilizada nos processos industriais, sem exceção, é composta por componentes heterogêneos e concentrados, o que impossibilita uma reciclagem completa, pois, assim como a energia, quando utilizada está sujeita a transformações irreversíveis (Cechin, 2010).

Não se pode negar que nos últimos anos houve avanços importantes na busca de novas alternativas para mudança da base energética, popularizando-se o uso de energias alternativas, como eólica, solar, biomassa, entre outras, mas é inegável que estas ainda configuram uma possibilidade distante de suprir o uso da força energética que moveu as estruturas do desenvolvimento capitalista ocidental, a dos combustíveis fósseis.
A noção de evolução, tanto cultural como social, tecnológica e política que se tem sobre a espécie humana se deu justamente pela sua capacidade de intervir nos recursos naturais à sua volta. Intervenções que foram aprimorando-se com o advento científico e o surgimento de instrumentos que permitiram, cada vez com mais rapidez, ao homem dominar os recursos à sua volta numa busca constante de satisfação.

\begin{abstract}
Uma delas era a capacidade dos humanos de transformar o ambiente de maneira que os beneficiava. Um dos primeiros exemplos é o modo como os humanos usavam o fogo. Ele foi usado para o calor e proteção durante a noite, para desmatar florestas, para quebrar pedra e para caçar e cozinhar animais. Isto trouxe em sua jornada importantes efeitos ecológicos, particularmente um aumento nos habitats das pastagens e, mais tarde, a extinção dos animais que foram inicialmente caçados $^{4}$ (Redclift, 1996, p. 45).
\end{abstract}

É evidente que esta interação não foi uma troca mútua de benefícios, foi de conquista e de degradação. A apropriação de espaços se deu não só pelo aumento populacional que, para os malthusianos, até poderia ser considerado matematicamente natural, mas, especialmente, pela necessidade que o homem teve de explorar e dominar todos os espaços a sua volta.

A Revolução Industrial no século XIX baseou-se na transformação da força motriz do calor (termodinâmica) e marcou uma ruptura da "questão produtividade" da "questão ecológica". Essa

\footnotetext{
${ }^{4}$ Tradução Livre. One was the ability of humans to transform the environment in ways that benefited them. An early example is the way humans used fire. It was used for warmth and protection during the night, for clearing forests, for breaking stone, and for hunting and cooking animals. This brought in its train important ecological effects, particularly an increase in grassland habitats end, later, the extinction of the animals which were initially hunted.
} 
revolução técnico-científica aplicada à produção de riquezas transformou os problemas ambientais de uma escala local para a esfera global. Isso despertou o interesse dos denominados engenheiros economistas, precursores da economia ecológica. Baseando-se nos princípios da termodinâmica, demonstraram e previram as repercussões ecológicas da revolução termoindustrial, princípio este que consiste em transformações irreversíveis nos grandes ciclos biogeoquímicos da biosfera.

Neste contexto, os denominados economistas ecológicos passaram a perceber ser imprescindível reconhecer que a Lei da Entropia está na origem da escassez econômica. Se esta lei não existisse, haveria a possibilidade de se reutilizar energia infinitamente; com isto o calor, por exemplo, que se origina de um pedaço de carvão não iria se dissipar, pois poderia ser novamente transformado em calor continuamente. Os motores poderiam funcionar com a mesma energia infinitamente. Não haveria diferença alguma entre os bens materiais e a terra, no sentido que o economista clássico David Ricardo previa no século XVIII.

Em semelhante mundo imaginário, puramente mecânico, não haveria real escassez de energia e de matérias-primas. Uma população numerosa quanto permitisse a extensão do nosso globo poderia mesmo viver para sempre. Um aumento na renda real por habitante poderia apoiar-se em parte numa velocidade maior de utilização (exatamente como no caso da circulação monetária) e em parte numa extração mineral amplificada (Georgescu-Roegen, 2012, p. 85).

Os economistas ecológicos, baseando-se nos princípios da termodinâmica, consideram que as consequências da Revolução "Termo" Industrial, iniciada no século XVIII e que dissipou a energia de forma irreversível, causaram transformações irreparáveis nos ciclos biogeoquímicos da biosfera. Para estes economistas, é preciso resgatar o caráter aberto do ecossistema, pois a lógica da análise econômica utilitarista da economia clássica o "fechou" e passou a considerar os serviços ecológicos da natureza - energia solar, recursos hídricos, solo, etc., - apenas como fonte inesgotável e/ou como fossa de resíduos.

Portanto, o ciclo fechado da economia neoclássica deve ser desconsiderado, pois a realidade da interação entre a produção de bens e o ecossistema planetário é aberta (Figura 2).

Os economistas ortodoxos costumam citar uma máxima que não tem autor conhecido, mas que foi popularizada na década de 1960 pelo economista liberal Milton Friedman no título de um de seus principais livros (que é dita, às vezes em forma de piada em reunião informais e às vezes também em reuniões sérias de homens de negócios, quando querem justificar cortes salariais e/ou de empregados nas empresas): "não existe almoço grátis".

Esta expressão tão compreensível pela ortodoxia econômica, pois significa que o preço de todas as coisas (bens) deve corresponder ao seu custo, nunca foi levada em conta ao se tratar dos desgastes dos recursos naturais. Se tivesse sido considerada, talvez hoje já existissem mecanismos eficientes de manter o restante dos recursos naturais do planeta, se não pela via de preços, pela parcimônia do princípio da precaução, outro fator pouco percebido pelos economistas do mainstream. Assim se pode afirmar também: não existe "almoço grátis" em relação aos desgastes dos recursos naturais, quem paga (pagará) por eles são (serão) os pobres desta e das gerações futuras. 


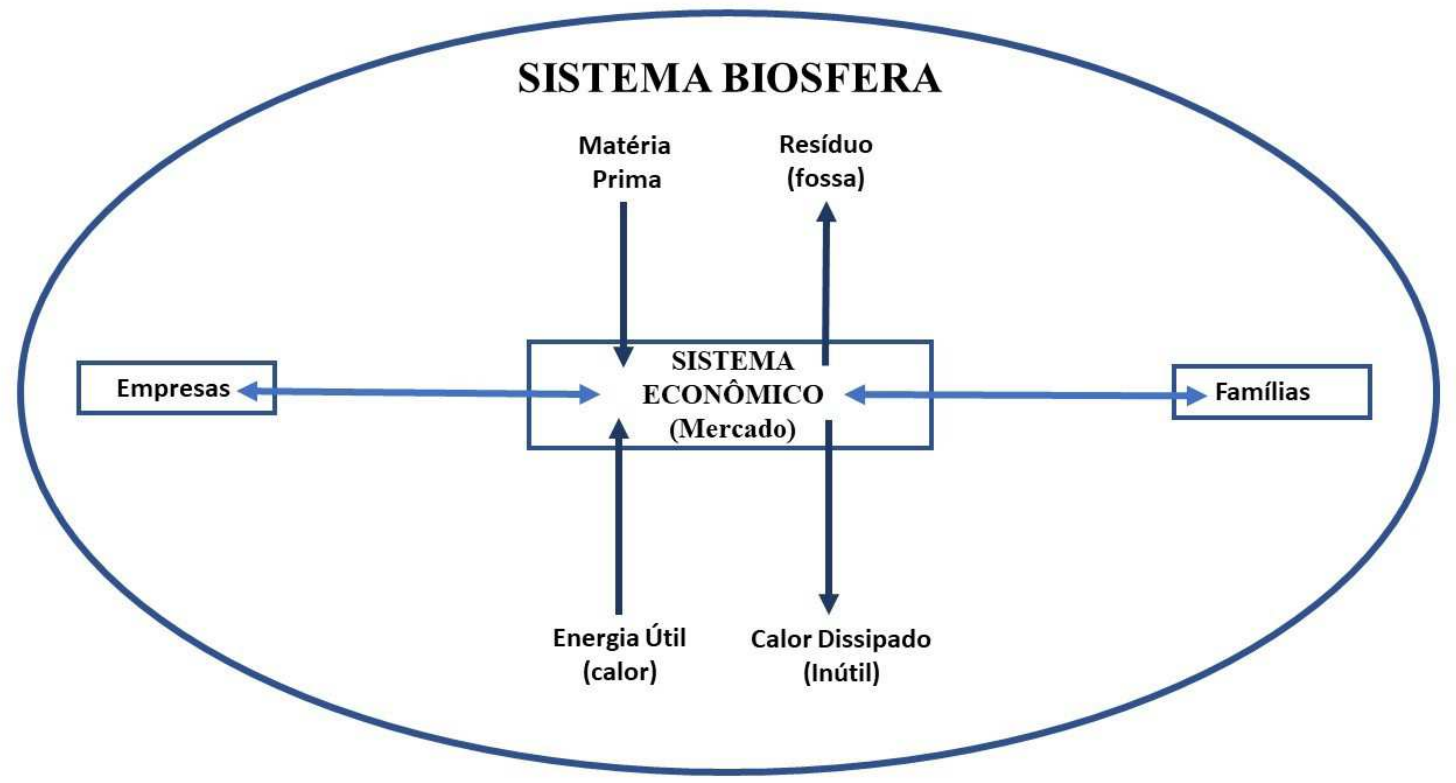

FIGURA 2 - Ciclo aberto da economia no ecossistema planetário (Biosfera).

FONTE: Rocha (2011).

\section{Considerações finais}

O paradigma científico da ciência econômica jamais foi confrontado, foram poucas, ou quem sabe nenhuma, mudanças epistemológicas da percepção das relações de troca e de desenvolvimento econômico após a obra do filósofo Adam Smith. Nenhuma escola do pensamento econômico, mesmo com concepções ideológicas e políticas totalmente opostas como a marxista, a liberal, a keynesiana, a institucionalista, etc., admitiu que o sistema econômico é aberto. A visão do sistema econômico circular e fechado orientou todas as escolas do pensamento econômico moderno. Georgescu foi o único que percebeu este erro. Esta incompatibilidade epistemológica com a economia convencional fez dele um "Dom Quixote" e, como este, se tornou ridicularizado ou esquecido no seu tempo.

No início do século XXI, as ideias de Georgescu-Roegen parecem estar passando por um processo de reabilitação, especialmente entre os economistas e outros estudiosos da denominada Economia Ecológica, mas que ainda está fora dos manuais clássicos da economia, pois os economistas do mainstream ainda não conseguem perceber a importância das abordagens ecológicas, físicas e químicas como parte das análises sobre os processos produtivos de riquezas.

O certo é que já são poucos os cientistas que persistem em desconsiderar das análises econômicas a perspectiva energética, pois esta passa por uma nova proposta de compreender a utilização dos recursos naturais na produção e consumo de 
riquezas. O que é urgente, como na frase inicial do prefácio, é considerar "os principais propulsores da economia como energia e ideias".

Para finalizar, vale remeter-se às palavras poéticas do próprio Georgescu, que compreendia que a ciência, arte, filosofia e poesia fazem parte de um mesmo todo, a práxis humana, sem que isto comprometa a rigidez dos argumentos: "Diferentemente do passado, o homem terá que retornar à ideia de que sua existência é uma dádiva do sol" (Georgescu-Roegen In: Cechin, 2010, p. 11).

Como limitação deste texto, salienta-se que é evidente que se ficou longe de conseguir abranger toda a obra de Georgescu-Roegen, temas como entropia, bioeconomia, decrescimento, entre outros, restaram, conscientemente, fora desta abordagem, pois aqui a ideia era fazer uma análise provocativa para outros pesquisadores, tanto para confrontar as possíveis convergências de análises que se possa ter sobre este texto, como também instigar novas abordagens analíticas da obra do esquecido "professor dos professores".

\section{Referências}

Brown L. R. Por uma sociedade viável. Rio de Janeiro: Fundação Getúlio Vargas, 1983.

Cechin, A. A. A natureza como limite da economia. A contribuição de Nicholas Georgescu-Roegen. São Paulo: Editora Senac/Edusp, 2010.

Fuks, M. Reflexões sobre o paradigma da economia ecológica para a gestão ambiental. Estudos Avançados, 26(74), 105-119, 2012.

Georgescu-Roegen, N. O decrescimento: entropia, economia. São Paulo: Editora Senac, 2012.

Jevons, W. S. The Theory of political economy. $5^{\text {a }}$. Ed. Nova
Iorque, 1957; reimpressão A.M. Kelley, 1965.

Mankiw, N. G. Introdução à Economia Princípios de Micro e Macroeconomia. Rio de Janeiro: Editora Campus, 1999.

Monbiot, G. A era do consenso: um manifesto para uma nova ordem mundial. São Paulo: Record, 2004.

Prado, E. F. S. A Ortodoxia Neoclássica. Estudos avançados, 15(41), 9-20, 2001.

Redeclift, M. Wasted: Couting the costes of Global Consumptin. London: Earthscan Publications, 1996.

Rocha, J. M. Sustentabilidade em Questão: Economia, Sociedade e Meio Ambiente. Jundiaí/SP: Paco Editorial, 2011.

Romeiro, A. R. Economia ou Economia Política da Sustentabilidade. In. May, P. H.; Lustosa, M. C.; Vinha, V. (Org.). Economia e Meio Ambiente. São Paulo: Atlas, 2003, p. 1-32.

Shumpeter, J. A. Teoria do Desenvolvimento Econômico. Uma investigação sobre lucros, capital, crédito, juro e o ciclo econômico. Tradução do texto em língua inglesa The Theory of Economic Development por Maria Sílvia Possas. São Paulo: Nova Cultura, 1997.

Souza, R. S. Entendendo a questão ambiental: temas de economia política e gestão do meio ambiente. Santa Cruz do Sul: Edunisc, 2000. 